\title{
Correction to: Ultra-trace Element Characterization of the Central Ottawa River Basin Using a Rapid, Flexible, and Low-Volume ICP-MS Method
}

\author{
Michael G. Babechuk ${ }^{1}$ (D) Edel M. O'Sullivan² ${ }^{2}$. Cora A. McKenna ${ }^{3}$ (D) . \\ Carolina Rosca ${ }^{4} \cdot$ Thomas F. Nägler $^{2}$ (D) $\cdot$ Ronny Schoenberg ${ }^{4}$ (i) $\cdot$ Balz S. Kamber $^{5}$ (D)
}

Published online: 28 July 2020

(c) Springer Nature B.V. 2020

\section{Correction to: Aquatic Geochemistry https://doi.org/10.1007/s10498-020-09376-w}

In the original publication of the article, the content under the section heading has been published incorrectly. Now the same has been corrected in this correction.

In the section heading 4.4 UT Results for SLRS-6 Test Experiments at $10 \times$ Dilution Factor and Detection Limit Barriers, line 11 should read as, "However, the precision is still $<5 \%$ for 19 elements, between 5 and $10 \%$ for 11 elements, and only $>10 \%$ for Be (14\%), $\mathrm{Nb}(13 \%), \mathrm{Lu}(11 \%)$, Hf (23\%), and W (12\%)".

Publisher's Note Springer Nature remains neutral with regard to jurisdictional claims in published maps and institutional affiliations.

The original article can be found online at https://doi.org/10.1007/s10498-020-09376-w.

Michael G. Babechuk

mbabechuk@mun.ca

1 Department of Earth Sciences, Memorial University of Newfoundland, St. John's, Canada

2 Institute of Geological Sciences, University of Bern, Bern, Switzerland

3 Department of Geology, University of Dublin - Trinity College, Dublin, Ireland

4 Isotope Geochemistry Group, Department of Geosciences, Eberhard Karls University of Tübingen, Tübingen, Germany

5 School of Earth and Atmospheric Sciences, Queensland University of Technology, Brisbane, Australia 